\title{
GMR
}

\section{Enhancement of pectinase production by ultraviolet irradiation and diethyl sulfate mutagenesis of a Fusarium oxysporum isolate}

\author{
L.B. Yin ${ }^{1,2,3}$, C.F. Zhang ${ }^{1}$, Q.L. Xia ${ }^{1}$, Y. Yang ${ }^{1}$, K. Xiao ${ }^{1}$ and L.Z. Zhao ${ }^{1,2,3}$ \\ ${ }^{1}$ Department of Biological and Chemical Engineering, Shaoyang University, \\ Shaoyang, Hunan, China \\ ${ }^{2}$ Soybean Processing Techniques of the Application and Basic Research Base \\ in Hunan Province, Shaoyang University, Shaoyang, Hunan, China \\ ${ }^{3}$ Technology Research and Design Center of Liwen Food Co., Ltd., \\ Shaoyang, Hunan, China \\ Corresponding author: L.Z. Zhao \\ E-mail: sys169@163.com
}

Genet. Mol. Res. 15 (3): gmr.15038986

Received July 21, 2016

Accepted August 1, 2016

Published September 23, 2016

DOI http://dx.doi.org/10.4238/gmr.15038986

Copyright (C) 2016 The Authors. This is an open-access article distributed under the terms of the Creative Commons Attribution ShareAlike (CC BY-SA) 4.0 License.

\begin{abstract}
Fusarium oxysporum strain BM-201 was treated with ultraviolet (UV) radiation to obtain a high pectinase-producing strain. Mutant UV-10-41 was obtained and then treated by diethyl sulfate. Next, the mutant UV-diethyl sulfate-43 derived from UV-10-41 was selected as high pectinase-producing strain. Mutant UV-diethyl sulfate-43 was incubated on slant for 10 generations, demonstrating that the pectinaseproducing genes were stable. Pectinase activity reached $391.2 \mathrm{U} / \mathrm{mL}$, which is $73.6 \%$ higher than that of the original strain.
\end{abstract}

Key words: Fusarium oxysporum; Mutant; Pectinase 


\section{INTRODUCTION}

Fusarium oxysporum is a soil-borne fungal pathogen that causes more than 100 types of wilting and vascular diseases in plants and produces pectinase (Enciso-Rodríguez et al., 2013; Silva et al., 2013). Pectinases are a large group of enzymes that hydrolyze pectin bonds and are widely applied in different industries. The most common application of pectinase is in the food industry to extract and clarify fruit and beverage juices (Adelakun et al., 2013, Sagu et al., 2014). Pectinases are also used in industrial processes, such as in ramie fiber degumming, oil extraction, coffee and tea fermentation, and industrial wastewater treatment (Esawy et al., 2013, Wu et al., 2013). Pectinases are produced by microbes, plants, and animals, but microorganisms are the most efficient source of the enzyme (Sharma et al., 2013b). Among the different types of microorganisms, pectinase production by filamentous fungi shows the most promise (Sharma et al., 2013a).

The treatment of spores and vegetative mycelium with different mutagens to screen for improved mutants among the surviving progeny has been recognized as an effective means of obtaining strains with improved potency (Khaliq et al., 2009, Romdhane et al., 2013). Strain mutation induction and screening techniques can improve microbes' pectinase yield by using different mutagens such as nitrous acid, diethyl sulfate (DES), and ethyl methyl sulfonate. When fungi are grown with mutagens at sub-lethal concentrations, the rate of enzyme production often increases. Exposure of thermophilic fungal conidia to UV and gamma $(\gamma)$ irradiation have also been used to obtain mutants that produce higher amounts of pectinase (Siripong et al., 2014). In addition, compound mutations may have synergistic effects and show better results than single mutations. In the present study, we aimed to generate improved strains of $F$. oxysporum using a combination of mutagenesis techniques, including UV irradiation and DES.

\section{MATERIAL AND METHODS}

\section{Microorganisms and media}

The F. oxysporum strain BM-201 was provided by Liwen Laboratory, Department of Biological and Chemical Engineering, Shaoyang University.

The culture of strain BM-201 was maintained on potato dextrose agar slants and Petri-plates. The mutant strain screening medium contained $(\mathrm{w} / \mathrm{v}): 0.5 \%$ orange peel powder, $0.2 \%\left(\mathrm{NH}_{4}\right)_{2} \mathrm{SO}_{4}, 0.001 \% \mathrm{FeSO}_{4} \cdot 7 \mathrm{H}_{2} \mathrm{O}, 0.1 \% \mathrm{KH}_{2} \mathrm{PO}_{4}, 0.06 \% \mathrm{MgSO}_{4}, 0.1 \% \mathrm{NaCl}$, and $1.5 \%$ agar powder (neutral $\mathrm{pH}$ ). Mutant strain enzyme production medium contained (w/v): $1.0 \%$ orange peel powder, $0.4 \%\left(\mathrm{NH}_{4}\right)_{2} \mathrm{SO}_{4}, 0.06 \% \mathrm{MgSO}_{4}, 0.1 \% \mathrm{NaCl}, 0.1 \% \mathrm{KH}_{2} \mathrm{PO}_{4}$, and $0.001 \%$ $\mathrm{FeSO}_{4} \cdot 7 \mathrm{H}_{2} \mathrm{O}$ (neutral $\mathrm{pH}$ ).

\section{Fungal inoculum preparation}

The microbial inoculum was prepared by suspending the spores from a potato dextrose agar slant in sterile water. The cells were diluted to $10^{6}$ spores $/ \mathrm{mL}$ and used for mutation induction and enzyme production.

\section{Mutagenesis by UV irradiation}

A $0.2-\mathrm{mL}$ spore suspension was spread onto the isolation plate. Plates were placed

Genetics and Molecular Research 15 (3): gmr.15038986 
$30 \mathrm{~cm}$ away from the center of an ultraviolet lamp (ZYT-DDC ultraviolet light, power of $30 \mathrm{~W}$ ) for $0,2,4,6,8,10,12$, or $14 \mathrm{~min}$. After UV irradiation, plates were incubated 2 days in the dark at $30^{\circ} \mathrm{C}$ to prevent photo-reactivation. A lethal dose curve of the parental strain was plotted, and mutants were isolated from plates showing $75-95 \%$ lethal rates. Individual large and white colonies were selected and streaked onto a potato dextrose agar plate. Among the selected strains, the mutant showing the highest pectinase yield was selected for further mutagenesis by DES.

\section{Mutagenesis by DES}

One milliliter DES of undiluted solution in a sterile reagent bottle was added to $4 \mathrm{~mL}$ anhydrous ethanol. This DES solution was added to $15 \mathrm{~mL}$ of the prepared spore suspension. After incubation on an oscillating shaker for $0,10,20,30,40,50,60$, and $70 \mathrm{~min}, 20 \mathrm{~mL}$ of sodium thiosulfate was added to terminate the mutagenesis reaction. Next, $0.2 \mathrm{~mL}$ processed spore suspension was spread onto the mutant screening plate. Subsequent treatments were the same as those used for UV mutagenesis. Finally, the mutant showing the highest pectinase yield was selected for further analysis.

\section{Enzyme production}

Liquid fermentations were cultured in 150-mL Erlenmeyer flasks inoculated with $10^{6}$ spores $/ \mathrm{mL}$ of the appropriate strain. The flasks were incubated in a rotary shaker at $30^{\circ} \mathrm{C}, 160$ $\mathrm{rpm}$. The fermentation broths were centrifuged at $4000 \mathrm{~g}$ for 20-25 min, and the supernatant was used to analyze pectinolytic activities (Pramod et al., 2014).

\section{Enzyme assay}

To draw the standard curve, $10 \mathrm{mg} / \mathrm{mL}$ galacturonic acid solution was prepared and then diluted to concentrations of $0,0.4,0.8,1.2,1.6$, and $2.0 \mathrm{mg} / \mathrm{mL}$. Each of the $0.5-\mathrm{mL}$ samples was first added to $1.5 \mathrm{~mL}$ citric acid-sodium citrate buffer and then $2.0 \mathrm{~mL}$ DNS reagent. The samples were boiled for $10 \mathrm{~min}$. Absorbance was measured at $550 \mathrm{~nm}$ to draw the standard curve.

To determine enzyme activity, $0.5 \mathrm{~mL}$ crude enzyme was added to $1.5 \mathrm{~mL}$ sodium pectate and the mixture was incubated at $50^{\circ} \mathrm{C}$ for $30 \mathrm{~min}$. Next, $2.0 \mathrm{~mL}$ DNS was added to the above mixture, and then the mixture was incubated in a boiling water bath for $10 \mathrm{~min}$ to stop the reaction. The catalytic activity of the enzyme was determined as the release of $1 \mathrm{mmol}$ galacturonic acid per unit volume, and unit time was defined as 1 unit of enzyme activity. Each test was repeated three times.

\section{Genetic stability of mutant producing enzyme}

The mutant obtained by mutagenesis and showing the highest pectinase producing activity was serially passaged for 10 generations in slant culture. For every two generations, pectinase activity was measured to determine the genetic stability of the mutant producing the enzyme.

Genetics and Molecular Research 15 (3): gmr.15038986 


\section{Relationship between pectinase production and fermentation time before and after mutagenesis}

The mutant finally obtained through screening and showing the highest pectinase yield and stable inheritance as well as the original strain were inoculated on a rotary shaker at $30^{\circ} \mathrm{C}, 160 \mathrm{rpm}$ for 7 days. Pectinase activity was measured every $24 \mathrm{~h}$.

\section{Results and discussion}

\section{Optimal mutagenesis dose}

The death rate of $F$. oxysporum strain BM-201 spores gradually increased with increasing UV exposure time. An exposure time of 14 min was found to be a lethal dose; however, the death rate was $60.5 \%$ after $8 \mathrm{~min}, 86.4 \%$ after $10 \mathrm{~min}$, and $97.2 \%$ after $12 \mathrm{~min}$ (Figure 1). Previous studies reported that a higher rate of positive mutation was observed at death rates of $70-90 \%$, at which mutagenic rates were improved. Therefore, the optimal UV mutagenesis dose was found to be $10 \mathrm{~min}$.

Different DES processing times were used to treat the spore suspension of $F$. oxysporum strain UV-10-41. DES processing for 40 and 60 min resulted in $58.4 \%$ and $95.6 \%$ death rates of the spores, respectively (Figure 1). The optimal DES mutagenesis treated time was found to be $60 \mathrm{~min}$.
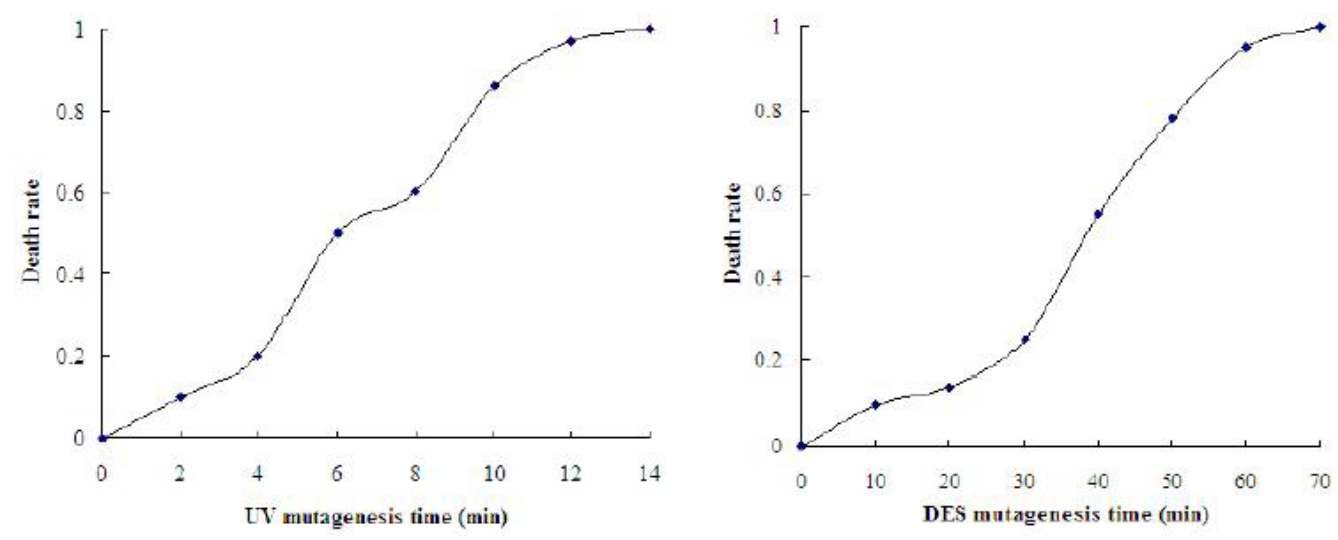

Figure 1. Dose-death curve of UV irradiation (left) and DES (right) treatment.

\section{Standard curve of D-galacturonic acid}

The standard curve of D-galacturonic acid is shown in Figure 2, and the concentration of D-galacturonic acid ranged from 0.4 to $2.0 \mathrm{mg} / \mathrm{mL}$. The corresponding absorbance was $0.04-0.70$. The equation for the standard curve was $\mathrm{y}=0.3884 \mathrm{x}-0.1307$. The correlation coefficient $r=0.9991>r_{0.01(n-2)}=0.977$, which was significant. Therefore, the correlation of the equation was high. 


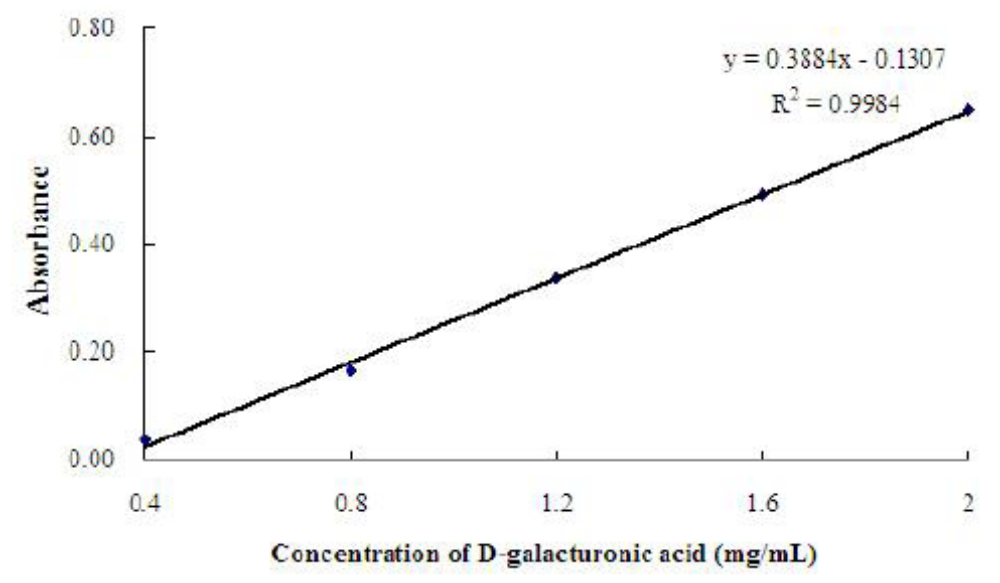

Figure 2. Standard curve of D-galacturonic acid.

\section{Results of UV mutagenesis}

A total of 84 mutants were obtained from the original strain BM-201 spore suspension irradiation by UV light for $10 \mathrm{~min}$. Among these mutants, 23 mutants exhibiting rapid growth and colonies larger than the parent stain were selected to measure pectinase production (Table 1). The mutant UV-10-41 showed the highest enzyme activity of $310.5 \mathrm{U} / \mathrm{mL}$, which was improved by $37.8 \%$ compared to the original strain. However, using Aspergillus niger CICC41254 as the original strain in ultraviolet mutagenesis, a previous study obtained mutant strains through solid state fermentation with pectinase activity improved by $54.24 \%$ (She et al., 2012). This may because the mutagenic effects in UV solid state fermentation are superior to those in submerged fermentation.

\section{Table 1. Mutagenic results of UV on strain BM-201.}

\begin{tabular}{l|c|c|c|c|c}
\hline Strains & Yield (U/mL) & Strains & Yield (U/mL) & Strains & Yield (U/mL) \\
\hline BM-201 & $225.4 \pm 0.8$ & UV-8-33 & $233.4 \pm 2.5$ & UV-10-59 & $215.4 \pm 0.7$ \\
\hline UV-10-3 & $256.3 \pm 1.2$ & UV-10-36 & $221.5 \pm 2.6$ & UV-10-61 & $224.0 \pm 2.3$ \\
\hline UV-10-9 & $258.6 \pm 0.7$ & UV-10-37 & $213.6 \pm 1.1$ & UV-10-63 & $235.6 \pm 0.8$ \\
\hline UV-10-16 & $210.4 \pm 2.1$ & UV-10-41 & $310.5 \pm 3.2$ & UV-10-66 & $212.7 \pm 2.8$ \\
\hline UV-10-20 & $214.8 \pm 1.5$ & UV-10-45 & $287.1 \pm 1.4$ & UV-10-69 & $236.8 \pm 2.4$ \\
\hline UV-10-22 & $198.3 \pm 1.3$ & UV-10-46 & $244.3 \pm 1.3$ & UV-10-74 & $246.2 \pm 1.1$ \\
\hline UV-10-27 & $241.1 \pm 3.1$ & UV-10-52 & $216.8 \pm 1.8$ & UV-10-77 & $231.3 \pm 1.7$ \\
\hline UV-10-28 & $250.6 \pm 2.9$ & UV-10-56 & $209.5 \pm 0.6$ & UV-10-78 & $226.8 \pm 1.2$ \\
\hline
\end{tabular}

\section{Results of DES mutagenesis}

The spore suspension of mutant UV-10-41 was mutagenized with 1\% DES for 10 min, and 79 single mutant colonies were obtained. Of these mutants, 24 gave rise to colonies that were up to 2 -fold larger than those of the parent strain. Their pectinase activity are shown in Table 2. Mutant UV-DES-43 produced the highest enzyme activity, reaching $391.2 \mathrm{U} / \mathrm{mL}$, which is $73.6 \%$ higher than the original strain.

Genetics and Molecular Research 15 (3): gmr.15038986 
Table 2. Mutagenic results of DES on strain UV-10-41.

\begin{tabular}{l|c|c|c|c|c}
\hline Strains & Yield (U/mL) & Strains & Yield $(\mathrm{U} / \mathrm{mL})$ & Strains & Yield (U/mL) \\
\hline UV-DES-2 & $347.3 \pm 0.9$ & UV-DES-26 & $365.2 \pm 1.1$ & UV-DES-41 & $363.4 \pm 2.4$ \\
\hline UV-DES-6 & $350.1 \pm 1.6$ & UV-DES-27 & $358.2 \pm 2.7$ & UV-DES-43 & $391.2 \pm 1.3$ \\
\hline UV-DES-9 & $317.9 \pm 2.2$ & UV-DES-28 & $341.6 \pm 3.0$ & UV-DES-45 & $301.8 \pm 2.1$ \\
\hline UV-DES-11 & $299.6 \pm 1.3$ & UV-DES-30 & $310.9 \pm 2.0$ & UV-DES-48 & $278.6 \pm 1.9$ \\
\hline UV-DES-14 & $234.2 \pm 0.8$ & UV-DES-32 & $325.7 \pm 1.6$ & UV-DES-51 & $286.4 \pm 1.8$ \\
\hline UV-DES-17 & $361.4 \pm 1.4$ & UV-DES-33 & $344.8 \pm 1.4$ & UV-DES-53 & $373.2 \pm 2.0$ \\
\hline UV-DES-18 & $275.8 \pm 1.6$ & UV-DES-38 & $312.4 \pm 2.2$ & UV-DES-54 & $345.1 \pm 0.9$ \\
\hline UV-DES-23 & $289.5 \pm 2.8$ & UV-DES-39 & $337.5 \pm 2.1$ & UV-DES-57 & $325.7 \pm 1.5$ \\
\hline
\end{tabular}

\section{Genetic stability test of pectinase production of mutant strain UV-DES-43}

Mutant UV-DES-43 was serially passaged for 10 generations, and pectinase activity was measured (repeat 3 times) every two generations (Table 3). Statistical analysis revealed that the differences in enzyme activity between $0,2,4,6,8$, and 10 generations were not significant $(\mathrm{P}>0.05)$. Thus, the mutant UV-10-43 showed highly stable pectinase production.

Table 3. Genetic stability of pectinase production of mutant strain UV-DES-43.

\begin{tabular}{|c|c|c|c|c|c|c|c|}
\hline & \multicolumn{6}{|c|}{ Generations } & \multirow{2}{*}{$P$ value } \\
\hline & 0 & 2 & 4 & 6 & 8 & 10 & \\
\hline Yield (U/mL) & $391.2 \pm 3.7$ & $389.8 \pm 4.0$ & $396.0 \pm 3.0$ & $395.5 \pm 4.7$ & $389.2 \pm 5.3$ & $389.3 \pm 5.4$ & 0.1297 \\
\hline
\end{tabular}

\section{Relationship between pectinase production and fermentation time before and after mutagenesis}

Mutant strain in the medium inoculated with spores of strain BM-201 and UVDES-43 were incubated at $30^{\circ} \mathrm{C}$ in a rotary shaker $(160 \mathrm{rpm})$ for 7 days. Pectinase activity was measured every $24 \mathrm{~h}$ and results are shown in Figure 3. As time increased, enzyme production by both BM-201 and UV-DES-43 also increased. Pectinase activity in UV-DES-43 reached a peak on the 4 th day $(391.8 \mathrm{U} / \mathrm{mL})$, while strain BM-201 showed peak production on the 5 th day $(225.7 \mathrm{U} / \mathrm{mL})$. After reaching a peak, the pectinase activity in both strains showed a small decrease. This may be because the cells began to die, and metabolite and enzyme binding reduced or eliminated enzyme activity.

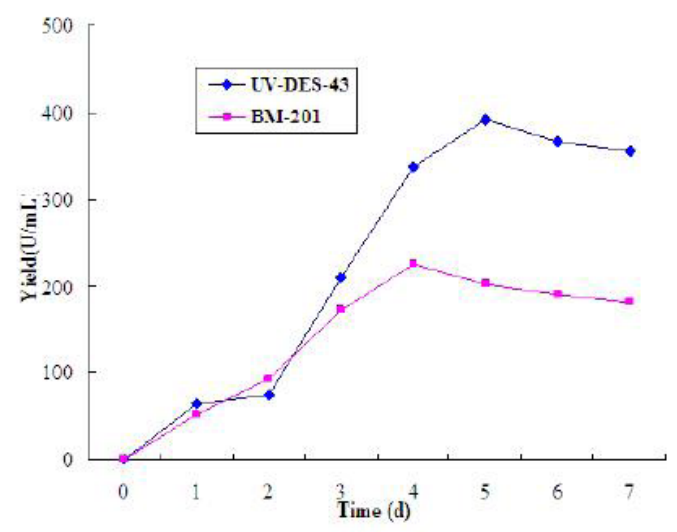

Figure 3. Relationship between enzyme production and fermentation time before and after mutation.

Genetics and Molecular Research 15 (3): gmr.15038986 


\section{CONCLUSIONS}

Fusarium oxysporum strain BM-201 was treated with ultraviolet radiation to develop a high pectinase-producing strain. Mutant UV-10-41 was obtained and then treated with DES. The mutant UV-DES-43 was further analyzed for its high pectinase production. Mutant UV-DES-43 was incubated in slant culture for 10 generations. Pectinase production remains stable over this time period. Pectinase activity reached $391.2 \mathrm{U} / \mathrm{mL}$, which was $73.6 \%$ higher than that in the original strain.

\section{Conflicts of interest}

The authors declare no conflict of interest.

\section{ACKNOWLEDGMENTS}

Research supported by the scientific research projects of Hunan Provincial Education Department (Grant \#13B110). This study was also partially supported by the Soybean Processing Techniques of the Application and Basic Research Base in Hunan Province (Grant \#2013TP4068) and Hunan Youth Talent Project (Grant \#S2016RSRCHX0156).

\section{REFERENCES}

Adelakun OE, Metclfe D, Tshabalala P, Stafford B, et al. (2013). The effect of pectinase enzyme on some quality attributes of a Nigerian mango juice. Nutr. Food Sci. 43: 374-383. http://dx.doi.org/10.1108/NFS-04-2012-0041

Enciso-Rodríguez FE, Gonz LEZC, Rodr guez EA, PEZ L, et al. (2013). Identification of immunity related genes to study the Physalis peruviana-Fusarium oxysporum pathosystem. PloS One 8: e68500.

Esawy MA, Gamal AA, Kamel Z, Ismail AMS, et al. (2013). Evaluation of free and immobilized Aspergillus niger NRC1 ami pectinase applicable in industrial processes. Carbohydr. Polym. 92: 1463-1469. http://dx.doi.org/10.1016/j. carbpol.2012.10.061

Khaliq S, Akhtar K, Afzal Ghauri M, Iqbal R, et al. (2009). Change in colony morphology and kinetics of tylosin production after UV and gamma irradiation mutagenesis of Streptomyces fradiae NRRL-2702. Microbiol. Res. 164: 469-477. http://dx.doi.org/10.1016/j.micres.2007.02.005

Pramod T, Siddalingeshwara K and Vishwanatha T (2014). Screening of Aspergillus niger strains for pectinolytic activity by solid state fermentation. J. Acad. Ind. Res. 2: 567.

Romdhane ZB, Tounsi H, Hadj-Sassi A, Hadj-Taieb N, et al. (2013). The constitutive production of pectinase by the CT1 mutant of Penicillium occitainis is modulated by pH. Appl. Biochem. Biotechnol. 169: 215-227. http://dx.doi. org/10.1007/s12010-012-9971-6

Sagu ST, Nso EJ, Karmakar S and De S (2014). Optimisation of low temperature extraction of banana juice using commercial pectinase. Food Chem. 151: 182-190. http://dx.doi.org/10.1016/j.foodchem.2013.11.031

Sharma A, Sheivastava A, Sharma S, Gupta R, et al. (2013a). Microbial pectinases and their applications. Biotechnology for Environmental Management and Resource Recovery. Springer.

Sharma N, Rathore M and Sharma M (2013b). Microbial pectinase: sources, characterization and applications. Rev. Environ. Sci. Biotechnol. 12: 45-60. http://dx.doi.org/10.1007/s11157-012-9276-9

She Q, Yang H, Yang G, Xue Y, et al. (2012). Breeding of high pectinase-producing Aspergillus niger strain by UV mutagenesis. China Brewing 31: 134-137.

Silva ADS, Oliveira EJD, Haddad F, Jesus OND, et al. (2013). Molecular fingerprinting of Fusarium oxysporum f. sp. passiflorae isolates using AFLP markers. Sci. Agric. 70: 108-115. http://dx.doi.org/10.1590/S0103$\underline{90162013000200008}$

Siripong P, Chuleekorn S and Duangporn P (2014). Enhanced cellulose production by ultraviolet (UV) irradiation and N-methyl-N'-nitro-N-nitrosoguanidine (NTG) mutagenesis of an Acetobacter species isolate. Afr. J. Biotechnol. 11: 1433-1442.

Wu R, He BH, Zhao GL, Qian LY, et al. (2013). Immobilization of pectinase on oxidized pulp fiber and its application in whitewater treatment. Carbohydr. Polym. 97: 523-529. http://dx.doi.org/10.1016/j.carbpol.2013.05.019

Genetics and Molecular Research 15 (3): gmr.15038986 